\title{
Asthma diagnosis and treatment - 1012. The efficacy of budesonide in the treatmetn of acute asthma in children: a double-blind, randomized, controlled trial
}

\author{
Abdullah A Alangari ${ }^{*}$, Nidal Malhis ${ }^{2}$, Mohamed Mubasher $^{3}$, Najwa Al-Ghamdi ${ }^{4}$, Mohammed Al-Tannir ${ }^{5}$, \\ Mohammed Riaz ${ }^{5}$, Dale Umetsu ${ }^{6}$, Saleh Al-Tamimi \\ From 2nd WAO International Scientific Conference (WISC 2012) \\ Hyderabad, India. 6-9 December 2012
}

\section{Background}

Current evidence suggests that inhaled glucocorticoids (IGC) have a more profound topical none genomic effect on bronchial airways as compared to systemic glucocorticoids. The value of adding IGC to current therapy of acute asthma is not well established.

\section{Methods}

We conducted a double-blind, randomized, two-arm, parallel groups, controlled clinical trial to compare the addition of budesonide $1500 \mathrm{mcg}$ or placebo (normal saline) to standard acute asthma treatment (albuterol and ipratropium bromide) administered in 3 divided mixed doses within 1 hour in the emergency department (ED). Children 2-12 years of age with moderate or severe acute asthma, scoring $8-15 / 15$ on a well-validated scoring system were included. Both groups received a single dose of prednisone $2 \mathrm{mg} / \mathrm{kg} /$ day (max. $60 \mathrm{mg}$ ) at the beginning of therapy. The primary outcome was admission rate within 2-4 hours from starting therapy.

\section{Results}

A total of 723 children were enrolled in the study over 17 months duration, of whom 139 were allowed to re-enroll and be randomized to constitute 906 randomization assignments (458 on the treatment group and 448 on the control group); with baseline mean $+\mathrm{SD}$ asthma score of $10.63+$ 1.73; age $5.52+2.76$ years; $35 \%$ girls; $30.8 \%$ (16.5\%) with baseline severe asthma score of $\geq 12(\geq 13)$. Statistical Analysis plan allowed for the potential dependency in response

${ }^{1}$ Pediatrics, King Saud University, College of Medicine, Riyadh, Saudi Arabia Full list of author information is available at the end of the article due to reenrollments of a subset of children, using Generalized Linear Mixed Modeling (GLMM) techniques. Baseline demographic and clinical characteristics were not significantly different between the two randomized groups. Seventy-five out of 458 (16.4\%) of the treatment group vs. $82 / 448(18.3 \%)$ of the control group were admitted, (OR 0.85 , CI: 0.59-1.23, p-value $=0.39$ ). Among the severe asthmatics with baseline score $\geq 13$, treatment vs. placebo group, GLMM adjusted admission rate was $30 \%$ vs. $47 \%$, indicating a $17 \%$ difference in admission rate in favor of the treatment group (adjusted OR of 0.49, CI: 0.25-0.95; $\mathrm{p}$-value $=0.035)$ that indicated a $51 \%$ reduction in the risk of admission for the treatment vs. control group.

\section{Conclusions}

Children with baseline severe asthma score $\geq 13$ who were treated with budesonide had a significant reduction in their admission rate.

\section{Author details}

${ }^{1}$ Pediatrics, King Saud University, College of Medicine, Riyadh, Saudi Arabia. ${ }^{2}$ Emergency Medicine, King Fahad Medical City, Riyadh, Saudi Arabia. ${ }^{3}$ King Fahad Medical City, Saudi Arabia. ${ }^{4}$ Pharm D, Pharmacy, King Fahad Medical City, Riyadh, Saudi Arabia. ${ }^{5}$ King Fahad Medical City, Riyadh, Saudi Arabia. ${ }^{6}$ Harvard University, MA, USA.

Published: 23 April 2013

\section{doi:10.1186/1939-4551-6-S1-P12}

Cite this article as: Alangari et al:: Asthma diagnosis and treatment 1012. The efficacy of budesonide in the treatmetn of acute asthma in children: a double-blind, randomized, controlled trial. World Allergy Organization Journal 2013 6(Suppl 1):P12. 